\title{
Vancomycin-resistant enterococci: The value of infection control and antibiotic control policy
}

\author{
Karl Weiss MD MSc FRCPC
}

K Weiss. Vancomycin-resistant enterococci: The value of infection control and antibiotic control policy. Can J Infect Dis Med Microbiol 2006;17(Suppl B):9B-12B.

\begin{abstract}
Vancomycin-resistant enterococci (VRE) represent a major challenge for the Canadian health care system. The clinical significance of VRE in the Canadian health care system has increased over the past two decades, with outbreaks reported in Ontario and Quebec, although most provinces have been affected. This organism has been a substantial human and financial burden for Canadian institutions. VRE have been shown to be associated with an increased mortality, a longer hospital stay and a much higher overall cost compared with vancomycinsusceptible strains.

Enterococci are now the third most important nosocomial pathogen in American intensive care units. The two most common species, Enterococcus faecalis and Enterococcus faecium, have shown remarkable adaptability in responding to antibiotics. The arrival of VRE in Canada has forced hospitals to implement stringent and costly infection control measures. A multifaceted approach, including antibiotic restriction and stringent infection control measures, is important in managing VRE prevalence in Canadian institutions.
\end{abstract}

Key Words: Infection control; Vancomycin-resistant enterococci

\section{Les entérocoques résistants à la vancomycine : L'utilité des mesures de lutte contre les infections et des restrictions d'emploi des antibiotiques}

Les entérocoques résistants à la vancomycine (ERV) constituent un problème de taille pour le système de soins de santé au Canada. L'importance clinique des ERV dans le système a augmenté au cours des deux dernières décennies; en effet, des éclosions ont été signalées en Ontario et au Québec, mais la plupart des provinces n'ont pas été épargnées. Les infections à ces micro-organismes imposent un lourd fardeau financier et humain aux établissements touchés. Les infections aux ERV sont associées à une mortalité accrue, à une prolongation des séjours à l'hôpital et à une augmentation très importante des frais généraux par rapport aux infections causées par des souches sensibles à la vancomycine. Les entérocoques forment maintenant la troisième famille d'agents pathogènes à l'origine des infections nosocomiales dans les services de soins intensifs en Amérique. Les deux espèces les plus courantes, Enterococcus faecalis et Enterococcus faecium, montrent une adaptabilité remarquable aux antibiotiques. La transmission de ces micro-organismes au Canada a obligé les hôpitaux à recourir à des mesures de lutte contre les infections, à la fois rigoureuses et coûteuses. La mise en œuvre d'une approche complexe, comportant entre autres une restriction d'emploi des antibiotiques et des mesures rigoureuses de lutte contre les infections, constitue un élément important de la gestion de la prévalence des infections aux ERV dans les établissements au Canada.

The origin of vancomycin resistance remains unclear. Avoparcin, a glycopeptide mainly used in Europe as a growth promoter in animal feeds, may be responsible for selecting VRE in farm animals. The latter may have been transmitted to humans through the food chain, or by direct contact to people close to the cattle industry (2).

\section{EPIDEMIOLOGY}

Since its initial identification in the late 1980s, VRE have been reported around the world, with variable prevalence among countries. Some European countries, such as France, have a high prevalence of VRE. In the United States, the National Nosocomial Infection Surveillance Program reported a continually increasing proportion of resistant enterococci throughout the 1990s, especially in the ICU setting (1). The percentage of VRE in American ICUs increased from $0.4 \%$ in 1989 to $23.2 \%$ in 1997 . In parallel, in the non-ICU setting, the rate went from $0.3 \%$ to $15.4 \%$ (1). VRE outbreaks in Canada have been reported mainly in Ontario and Quebec, although most other provinces have also been affected (British Columbia and Nova Scotia) (4). These outbreaks were contained after introducing stringent infection control measures. One study involving 38 medical centres described the prevalence antibiotics. 
TABLE 1

Recommendations for limiting vancomycin-resistant enterococci transmission

Precautions
Private room or cohorting
Gloves
Removal of gloves and gown before leaving the room
Washing of hands with an antiseptic soap or a waterless antiseptic agent
Gowns (most of the time)
Rectal cultures (roommates and screening)
Dedicated equipment
Precautions in place until patient's cultures are negative on at least
three occasions, one week apart
Colonized and infected patients identified when transferred to another
facility or within the hospital
Tagging of colonized or infected patients on a computer system
(for readmission or outpatient visits)
Patients cohorting
Assigning of patients to geographical cohorts
Staff cohorting

Data from reference 3

of VRE in enterococci isolated from the urinary tract. Only three strains were found in Canada, compared with 697 in the United States (5). An international study showed a much higher proportion of VRE in the United States than in Canada and Latin America. For example, the VRE rate was $16.3 \%$ versus $1.3 \%$ in bloodstream isolates in the United States and Canada, respectively (6).

VRE in Canada were mainly an issue of outbreaks in selected high-risk units, including nephrology wards, hemodialysis and ICUs. The aggressive approach taken by Canadian institutions when these outbreaks were recognized may have limited the spread of this microorganism.

\section{RISK FACTORS}

Unlike other antibiotic-resistant microorganisms, such as Streptococcus pneumoniae or the newly problematic communityacquired methicillin-resistant Staphylococcus aureus, VRE have been restricted to high-risk patients. Virtually all VRE-colonized or -infected patients had at least one significant medical problem (2). The principally identified risk factors were severe underlying conditions, such as immunosuppression, intraabdominal surgery, hemodialysis and previous antimicrobial therapy with vancomycin or cephalosporins $(2,4)$. Once colonized, only a small fraction of patients develop a significant infection. In a prospective study (7) of patients with liver and kidney transplants, only six of 52 patients $(11.3 \%)$ initially colonized developed an infection.

\section{CLINICAL IMPLICATIONS OF VRE}

VRE have been shown to be associated with an increased mortality risk, longer hospital stay and much higher overall cost compared with vancomycin-susceptible strains (8). In one study, Lucas et al (9) reported the attributable crude fatality rate to be $27 \%$ for vancomycin-susceptible enterococci and $45 \%$ for VRE. However, patients with VRE infections are in poorer medical condition, and this may contribute to some mortality differences.
MINC, = DO NOT COPY

TRANSMISSION AND INFECTION CONTROL

VRE have been shown to spread rapidly in outbreak situations. Contact precautions, patient cohorting and staff cohorting have been recommended to limit the transmission of VRE (3) (Table 1). During outbreaks of VRE, there is extensive colonization of patient and staff digestive tracts. This asymptomatic carriage can last months or years (10). After experimental inoculation, VRE can survive on hands for approximately $30 \mathrm{~min}$. Alcohol-based disinfectants seem to be very effective in killing the microorganism, while iodine-based solutions are less effective (11). During VRE outbreaks, the environment has also been shown to be highly contaminated (12). Asymptomatic stool carriage of VRE is common and contributes to the continuing propagation of the outbreak. Toilets and electronic thermometers have both been reported to be vectors for transmission $(10,13)$.

Costly, time-consuming and cumbersome infection control techniques have been suggested to control VRE. The efficacy of glove use is well documented, but does not eliminate the need for a thorough handwashing (14). The addition of gowns is more controversial. One study (14) reported no added benefit to wearing a gown, but compliance with recommended precautions increased with grown use. Puzniak et al (15) indicated that $58 \mathrm{VRE}$ cases were averted during an 18-month period when gowns were worn in addition to gloves. A mathematical model comparing different models of care showed an average of 3.81 secondary cases when no measures were in place, compared with 0.7 when standard and rigorous infection control policies were implemented. Handwashing and staff cohorting were the most important measures (16).

Implementing these measures in VRE outbreaks is costeffective; one study demonstrated a net savings of US $\$ 189,318$ for a one-year period (17). Infection control measures have, to date, been the most effective interventions to curb VRE rates. In one institution, assigning patients to geographical cohorts, assigning nurses to patient cohorts, wearing gowns and gloves, and educating staff and patients decreased the VRE bloodstream infection rate from 2.1 patients per 1000 patient-days to 0.45 patients per 1000 patient-days $(\mathrm{P}=0.04)$. VRE colonization also decreased from 20.7 patients per 1000 patient-days to 10.3 patients per 1000 patient-days $(\mathrm{P}<0.001)(18)$.

\section{ANTIBIOTIC USE}

Several studies have explored modification of hospital formularies to decrease the prevalence of VRE (19-23). In general, the available data raise some controversy (Table 2). In an outbreak situation in a Canadian hospital, cephalosporin use was identified as the only independent risk factor for VRE (OR 13.8; 95\% CI 2.5 to 76.3) (4). Quale et al (21) showed a decreased rate of VRE fecal colonization from $47 \%$ to $15 \%(\mathrm{P}<0.001)$ after restricting the use of third-generation cephalosporins, clindamycin and vancomycin. A third study (20) conducted in a trauma burn unit concluded that switching from cephalosporins to piperacillin-tazobactam had a positive impact on VRE prevalence. The introduction of piperacillin-tazobactam was associated with a significant decrease of VRE in this setting (Figure 1). A very large study conducted in 126 adult ICUs in the United States from January 1996 to July 1999 indicated that higher rates of vancomycin or third-generation cephalosporin use were independently associated with VRE prevalence (22). However, other studies showed no impact on the VRE prevalence when restricting the use of third-generation cephalosporins (23). VRE 
TABLE 2

\section{COPYRIGHT PULSUS GROUP INC. " DO NOT COPY}

Vancomycin-resistant enterococci (VRE) and antibiotics

\begin{tabular}{|c|c|c|}
\hline Study & Intervention and results & Statistics \\
\hline Loeb et al (4) & Case-control study of VRE colonization; cephalosporins were the only modifiable risk factor & OR $13.8(95 \% \mathrm{Cl} 2.5$ to 76.3$)$ \\
\hline Quale et al (21) & $\begin{array}{l}\text { Restriction on vancomycin }+ \text { third-generation cephalosporins; replaced third-generation cephalosporins } \\
\text { with beta-lactamase inhibitor. VRE colonization was } 47 \% \text { to } 15 \%\end{array}$ & $\begin{array}{l}\text { VRE colonization: } 47 \% \text { to } 15 \% \\
\qquad(P<0.001)\end{array}$ \\
\hline Lautenbach et al (23) & VRE prevalence increased from $17.4 \%$ to $29.6 \%$ (10 years); vancomycin and third-generation & $\mathrm{P}<0.001$ \\
\hline
\end{tabular}
cephalosporins had little impact

Stiefel et al (19) Retrospective study in four teaching hospitals; piperacillin-tazobactam was not associated with decreasing VRE rates
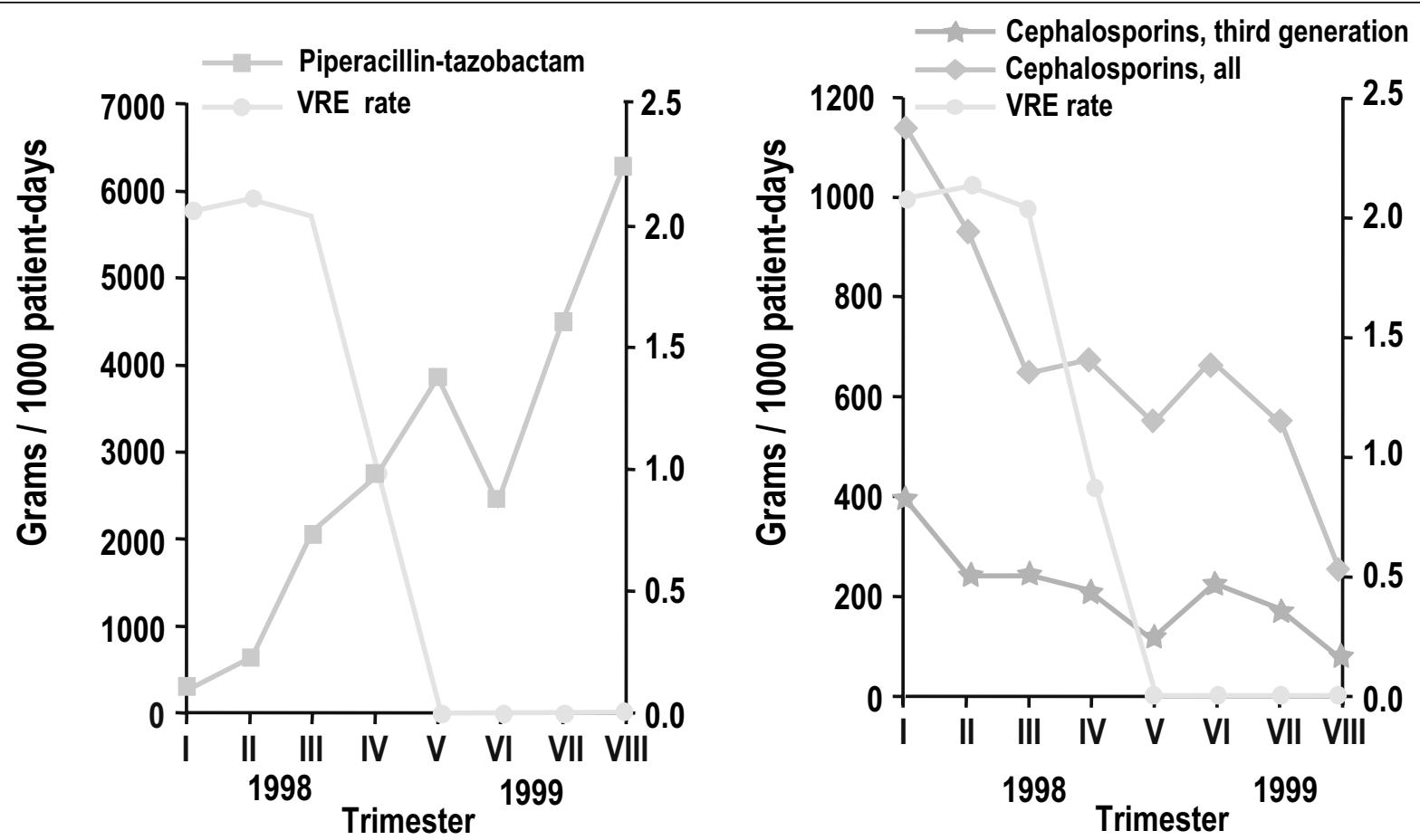

Figure 1) Formulary intervention: third-generation cephalosporins replaced by piperacillin-tazobactam. VRE Vancomycin-resistant enterococci. Adapted from reference 20

prevalence increased from $17.4 \%$ to $29.4 \%$ over a 10 -year period in spite of a $85.8 \%$ reduction in third-generation cephalosporin use (23). The impact of antimicrobial restrictions on VRE prevalence remains unresolved. The most prudent approach is to monitor the type and the quantity of antibiotics being used, notably beta-lactams and vancomycin, on an institutional basis.

\section{CONCLUSIONS}

VRE have emerged as a major threat in many countries, but have had limited epidemiological impact in Canada. Control of this microorganism requires a multifaceted approach. Rigorous infection control measures have been proven to be efficient in controlling outbreaks. Published guidelines (3) from the Hospital Infection Control Practices Advisory Committee recommend the use of contact precautions. Some special attention has to be given to the environment in terms of cleaning. Dedicated equipment for colonized or infected patients is also recommended.

Antibiotic restriction may have a role to play but, to date, has had limited impact. The debate remains open on how to use different agents to modify VRE prevalence in institutions.

\section{REFERENCES}

1. Martone WJ. Spread of vancomycin-resistant enterococci: Why did it happen in the United States? Infect Control Hosp Epidemiol 1998;19:539-45.

2. Bensoussan R, Weiss K, Laverdiere M. Vancomycin-resistant Enterococcus. Scand J Gastroenterol 1998;33:1233-8.

3. Recommendations for preventing the spread of vancomycin resistance: Recommendations of the Hospital Infection Control Practices Advisory Committee (HICPAC). Am J Infect Control 1995;23:87-94

4. Loeb M, Salama S, Armstrong-Evans M, Capretta G, Olde J. A case-control study to detect modifiable risk factors for colonization with vancomycin-resistant enterococci. Infect Control Hosp Epidemiol 1999;20:760-3.

5. Zhanel GG, Laing NM, Nichol KA, et al. Antibiotic activity against urinary tract infection (UTI) isolates of vancomycinresistant enterococci (VRE): Results from the 2002 North American Vancomycin Resistant Enterococci Susceptibility Study (NAVRESS). J Antimicrob Chemother 2003;52:382-8.

6. Low DE, Keller N, Barth A, Jones RN. Clinical prevalence, antimicrobial susceptibility, and geographic resistance patterns of enterococci: Results from the SENTRY Antimicrobial Surveillance Program, 1997-1999. Clin Infect Dis 2001;32(Suppl 2):S133-45.

7. Patel R, Allen SL, Manahan JM, et al. Natural history of vancomycin-resistant enterococcal colonization in liver and kidney transplant recipients. Liver Transpl 2001;7:27-31. 
8. Salgado CD, Farr BM. Outcomes associated with vancomycinresistant enterococci: A meta-analysis. Infect Control Hosp Epidemiol 2003;24:690-8.

9. Lucas GM, Lechtzin N, Puryear DW, Yau LL, Flexner CW, Moore RD. Vancomycin-resistant and vancomycin-susceptible enterococcal bacteremia: Comparison of clinical features and outcomes. Clin Infect Dis 1998;26:1127-33.

10. Livornese LL Jr, Dias S, Samel C, et al. Hospital-acquired infection with vancomycin-resistant Enterococcus faecium transmitted by electronic thermometers. Ann Intern Med 1992;117:112-6.

11. Wade JJ, Desai N, Casewell MW. Hygienic hand disinfection for the removal of epidemic vancomycin-resistant Enterococcus faecium and gentamicin-resistant Enterobacter cloacae. J Hosp Infect 1991;18:211-8.

12. Boyce JM, Opal SM, Chow JW, et al. Outbreak of multidrug resistant Enterococcus faecium with transferable vanB class vancomycin resistance. J Clin Microbiol 1994;32:1148-53.

13. Noble MA, Isaac-Renton JL, Bryce EA, et al. The toilet as a transmission vector of vancomycin-resistant enterococci. J Hosp Infect 1998;40:237-41.

14. Slaughter S, Hayden MK, Nathan C, et al. A comparison of the effect of universal use of gloves and gowns with that of glove use alone on acquisition of vancomycin-resistant enterococci in a medical intensive care unit. Ann Intern Med 1996;125:448-56.

15. Puzniak LA, Gillespie KN, Leet T, Kollef M, Mundy LM. A costbenefit analysis of gown use in controlling vancomycin-resistant Enterococcus transmission: is it worth the price? Infect Control Hosp Epidemiol 2004;25:418-24.

16. Austin DJ, Bonten MJ, Weinstein RA, Slaughter S, Anderson RM. Vancomycin-resistant enterococci in intensive-care hospital settings: Transmission dynamics, persistence, and the impact of infection control programs. Proc Natl Acad Sci USA 1999;96:6908-13.
17. Montecalvo MA, Jarvis WR, Uman J, et al. Costs and savings associated with infection control measures that reduced transmission of vancomycin-resistant enterococci in an endemic setting. Infect Control Hosp Epidemiol 2001;22:437-42.

18. Montecalvo MA, Jarvis WR, Uman J, et al. Infection-control measures reduce transmission of vancomycin-resistant enterococci in an endemic setting. Ann Intern Med 1999;131:269-72.

19. Stiefel U, Paterson DL, Pultz NJ, Gordon SM, Aron DC, Donskey CJ. Effect of the increasing use of piperacillin/tazobactam on the incidence of vancomycin-resistant enterococci in four academic medical centers. Infect Control Hosp Epidemiol 2004;25:380-3.

20. May AK, Melton SM, McGwin G, Cross JM, Moser SA, Rue LW. Reduction of vancomycin-resistant enterococcal infections by limitation of broad-spectrum cephalosporin use in a trauma and burn intensive care unit. Shock 2000;14:259-64.

21. Quale J, Landman D, Saurina G, Atwood E, DiTore V, Patel K. Manipulation of a hospital antimicrobial formulary to control an outbreak of vancomycin-resistant enterococci. Clin Infect Dis 1996;23:1020-5.

22. Fridkin SK, Edwards JR, Courval JM, et al; Intensive Care Antimicrobial Resistance Epidemiology (ICARE) Project and the National Nosocomial Infections Surveillance (NNIS) System Hospitals. The effect of vancomycin and third-generation cephalosporins on prevalence of vancomycin-resistant enterococci in 126 U.S. adult intensive care units. Ann Intern Med 2001;135:175-83.

23. Lautenbach E, LaRosa LA, Marr AM, Nachamkin I, Bilker WB, Fishman NO. Changes in the prevalence of vancomycin-resistant enterococci in response to antimicrobial formulary interventions: Impact of progressive restrictions on use of vancomycin and thirdgeneration cephalosporins. Clin Infect Dis 2003;36:440-6. 


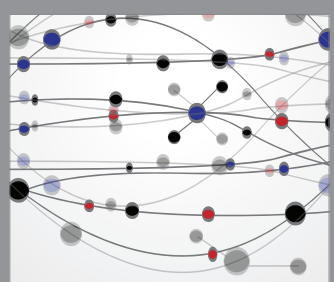

The Scientific World Journal
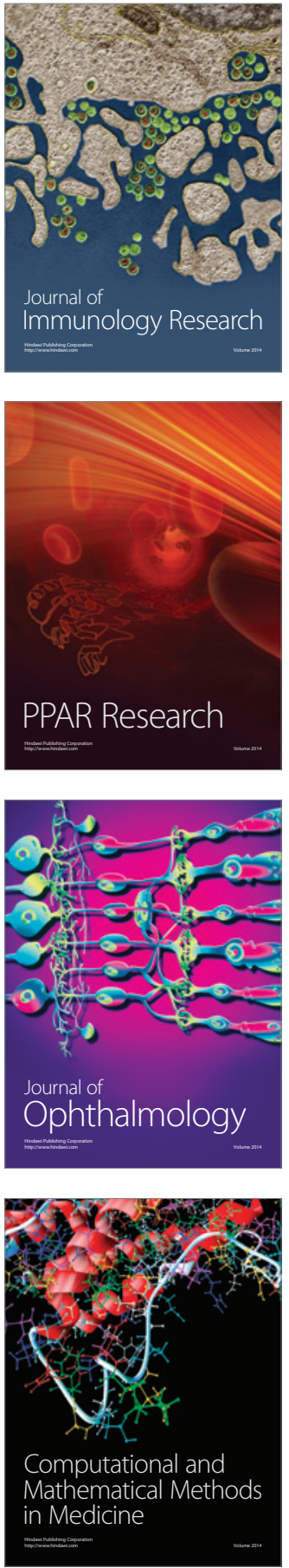

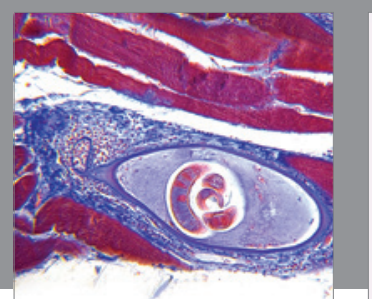

Gastroenterology Research and Practice

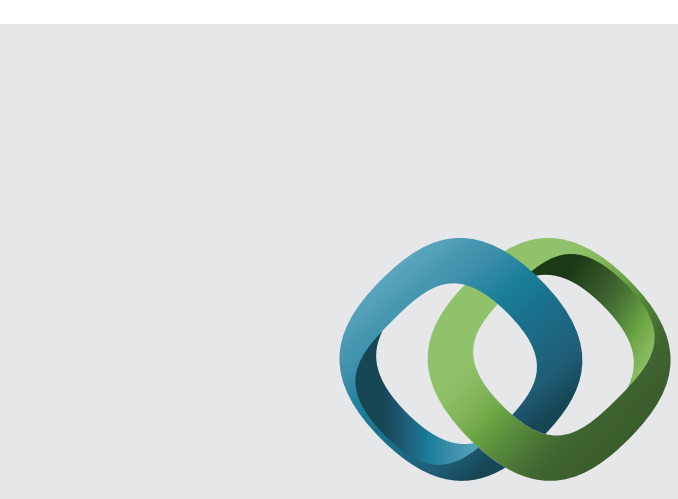

\section{Hindawi}

Submit your manuscripts at

http://www.hindawi.com
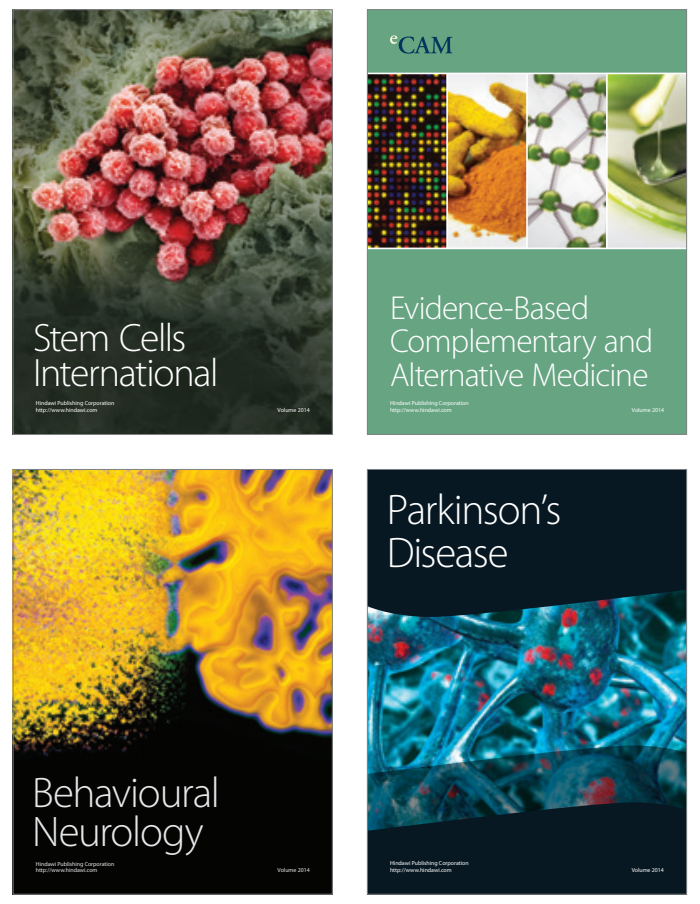
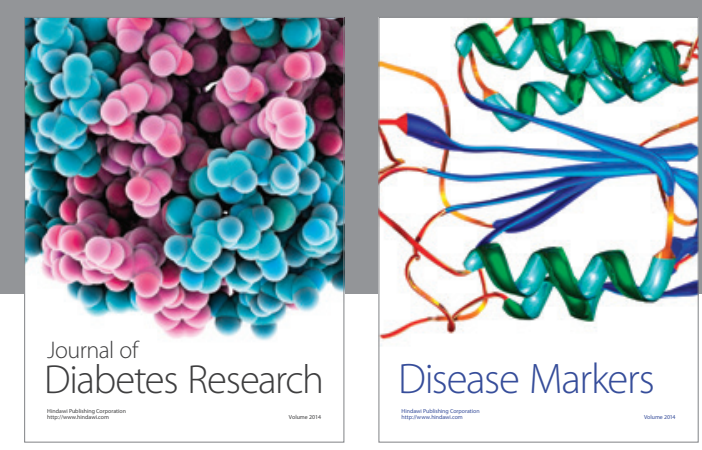

Disease Markers
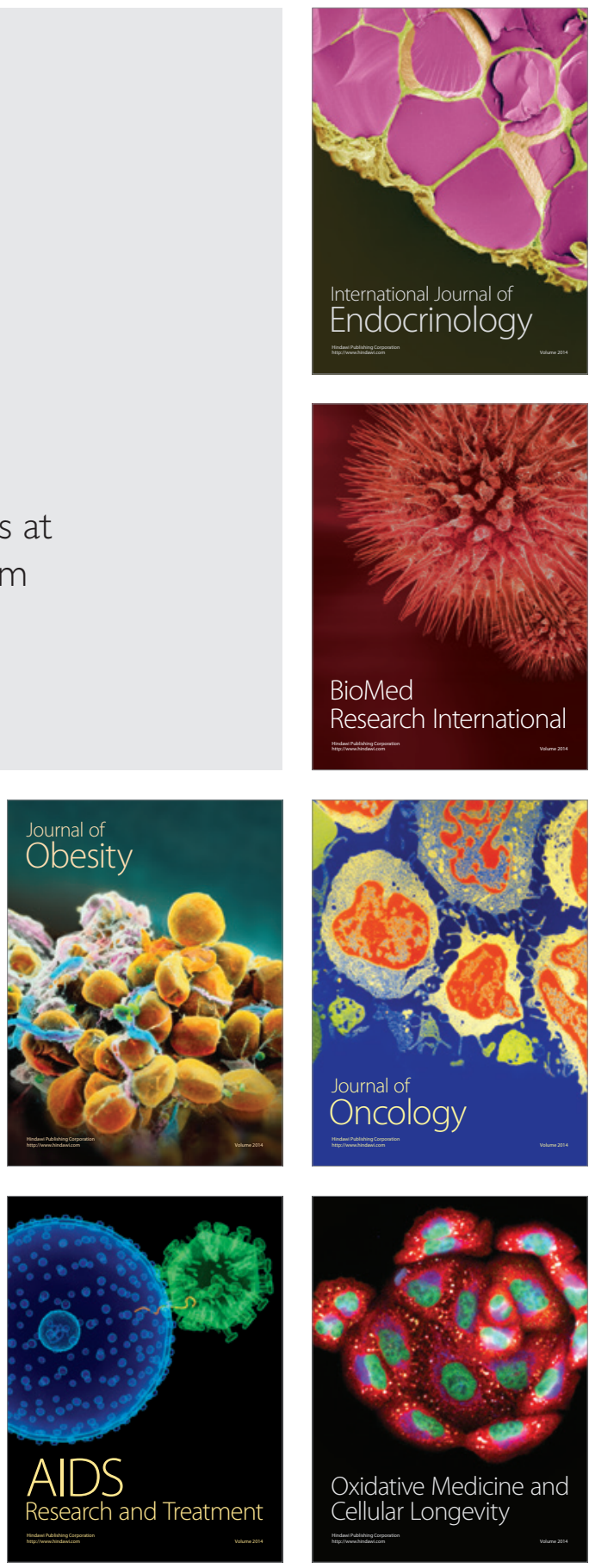